\title{
INTERSECTION LEVEL OF SERVICE FOR THE CICLORUTA BICYCLE INFRASTRUCTURE IN BOGOTA, COLOMBIA

\author{
Inah Eteng Okon
}

Associate Professor, Department of Geography and Environmental Science, University of Calabar, Calabar, PMB 1115, Nigeria.

Email: inah.okon@unical.edu.ng

Article History: Received on $24^{\text {th }}$ July 2021, Revised on $5^{\text {th }}$ August 2021, Published on $10^{\text {th }}$ August 2021

\begin{abstract}
Purpose of the study: A satisfaction audit for use of cycling mode is aimed at the promotion of non-motorized transport which is safe, comfortable, economical and energy-efficient as critical for urban sustainability. The study examined the level of satisfaction that cyclists derive from the cicloruta based on the intersections in the network.
\end{abstract}

Methodology: The methodology involved the use of primary data such as 680 perceptions of satisfaction ratings; physical and operational characteristics of road infrastructure (measurement and observational) data; and shapefile of the cicloruta. The relationship between variables was examined using correlation statistics, while the ordered probit model was used to estimate the parameter, predicted logit and predicted probabilities.

Main Findings: An estimated model for intersection bicycle level of service (IntBLOS) revealed that the volume of vehicular and total intersection legs are factors with a high influence on cyclist's level of satisfaction. The model was used in ArcGIS to compute IntBLOS scores at both segment and facility levels. Since segments are not independent of intersections or vice versa, the study used these two independent models to estimate the level of bicyclist's satisfaction.

Applications of this study: This study undoubtedly takes a step towards demonstrating a non-motorised transport infrastructure audit which can help address specific concerns of cyclists and thus enhance ridership in the study area. Elsewhere, especially in the developing countries applicability of this methodology shall be with modifications on measurement and observation data that reflects peculiar local traffic situations.

Novelty/Originality of this study: The findings of this paper has stimulated further conversation on the factors of cycling in the city with its ambitious cycling infrastructure. It has also provided planners with an infrastructure audit methodology to enhance cycling safely and sustainably. The study recommended proper enlightenment of motorists and cyclists alike on their right of way and most importantly, the redesign of most intersections in the study area to reflect the present cycling realities of Bogota.

Keywords: Bicycle Level of Service, Cicloruta, Intersection Level of Service, Satisfaction.

\section{INTRODUCTION}

The most essential function of transportation is providing mobility for people and goods. This is why the Florida Department of Transportation level of service (FDOT, 2009) identified four dimensions of transportation. These include the quality of transportation which deals with the traveller's satisfaction; the quantity of travel that deals with the magnitude of use of a facility or service; accessibility as the ease with which travellers can engage in desired activities; and capacity utilization as the number of operations relative to capacity. This is based on what highway capacity manual ( measure or measures that represent the quality of service'. There is therefore the need for quantitative stratification of a performance measure(s) that represent the quality of service that ranges from 1-6, representing highly satisfied, moderately satisfied, a little satisfied, a little dissatisfied, moderately dissatisfied, and highly dissatisfied conditions respectively.

Moreover, the need for the development of transportation facilities and for that matter non-motorized becomes imperative given the more than 7 million inhabitants in Bogota city with various mobility needs. It is already established that many governments at local and federal levels are investing huge financial resources in non-motorized transportation infrastructures. In 1999 for example, the city of Bogota built a high-capacity bus system (TRANSMILENIO) to address the transport needs of residents. The cicloruta which is about $300 \mathrm{~km}$ was followed shortly in 2000. It is estimated that about US\$180 million was spent on this infrastructure. It is therefore not unlikely that there may be other factors that encourage its use or otherwise.

Intersection presents some of the most complex components of many transportation networks. The majority of intersection researches were either based partly on or a combination of methodology from leading bicycle level of service studies (Epperson, 1994; Harkey, Reinfurt, Knuiman, 1998; Landis, 1994; Landis, Vattikut, Brannick, 1997; Sorton, Walsh, 1994). Other studies recently focused on the bicycle comfort and level of service (Monox, Monzon \& Lopez, 2016; Fu \& Farber, 2017; Fernandez-Heredia, Jara-Diaz \& Monzon, 2016) and satisfaction from bicycle parking and level of service (Heinen \& Buehler, 2019). An intersection design with consideration for the safety of bicyclists can provide transport planners with basic tools for an evaluation of satisfaction levels. Although, it is difficult to scientifically prove the extent to which perception of safety at intersections has a direct correlation with the use of 
bicycle infrastructure since many other factors along with the segment influence satisfaction. There is overwhelming evidence on the need for intersection designs that accommodate bicyclists.

However, essential data and generally accepted methodologies for measuring the use of these facilities are unavailable for planning and management purposes leading to most methodologies adopting tools and methods developed for motor traffic and associated traffic conditions (Hoogendoorn \& Daamen, 2016; Jiang, Hu, Wu \& Song, 2016). It is therefore difficult to achieve 'evidence-based choices among investment alternatives and to optimize management of the infrastructure and transportation systems' due largely to lack of data and necessary tools for estimating facility use (Lindsey, Hoff, Hankey, Wang, 2012). Transportation planners and engineers alike need information and scientific tools for estimating bicycle traffic volume and pattern of facility use. The theme of this research, therefore, emerged to evaluate the level of satisfaction of bicyclists thereby developing suitable indicators that help policymakers prioritize their investments in new and existing bicycle infrastructures. The aim of the study, therefore, was to present a methodology that offers bicycle infrastructure audit which is aimed at enhancing cycling in the study area, especially intending to estimate intersection level of service model for transport planners in Bogota and other cities. Relevant segments of the bicycle road network can thus be improved or redesigned especially in terms of intersection to enhance the capability of the cicloruta to accommodate bicycle use.

\section{LITERATURE REVIEW}

Intersections are a very important component of cycling infrastructure that determines the level of satisfaction in respect of cyclists' comfort (Blau \& Nasar, 2018). Wang and Nihan (Wang, Nihan, 2004) developed a probability-based methodology for estimating bicycle-motor vehicle accident risks at intersections in the Tokyo Metropolitan area. The estimated three negative binomial regression models using the maximum likelihood method based on 4-year (19921995) data set from 115 signalized intersections. The study further revealed that wider road median has higher bicyclemotor vehicle accident risk which is due to poor vision angle and thus presents difficulty to detect opposite through vehicles. In other to examine accident levels due to drivers scanning behaviour at two intersections in the city of Helsinki, Summala, Pasanen, Räsänen, and Sievänen (1996) 'first tested an explanation that drivers turning right simply focus their attention on the cars coming from the left-those coming from the right posing no threat to them and fail to see the cyclist from the right early enough'. They used hidden cameras that recorded these driver's behaviour and supported the hypothesis that 'drivers turning right scanned the right leg of the T-intersection less frequently and later than those turning left. This suggests that drivers develop a visual scanning strategy to concentrate on more dangers than fewer ones like the cyclists, and therefore result in frequent collisions with cyclists. Because of their findings that high-speed countermeasures like bumps, forms another vital component of driver's visual scanning strategy, the paper suggested high safety intersection designs including the use of speed limits (Summala, et al., 1996). Similarly, Xu, Liu, Song and Jin (2018) opined that 'overtaking is a high-frequency behaviour' as far as heterogenous bicycle flow is concerned. Gårder, Leden, and Thedéen (1994) examined the safety implications of bicycle paths at signalized intersections using the Bayesian technique to predict a 40 per cent probability of likely accidents involving cyclists if a cycle path is planned across a signalized intersection.

Videos of 16 segments which were carefully collected and showed to participants who rated their level of satisfaction using a 6-point scale (A-F: 'highly satisfied' to 'highly dissatisfied') were used (Okon, Brussel, van den Bosch, Moreno, \& van Maarseveen, 2017). This is equivalent to 1360 segments. The research employed ordered probability models to estimate random parameters of cyclists LOS perception to account for unobserved heterogeneity for all respondents. Bicycle level of service (BLOS) was strongly influenced by side path separation $(\beta=0.605, p<0.05)$; vehicle speed $(\beta=0.717, \mathrm{p}<0.05)$; motorized traffic volume $(\beta=-0.381, \mathrm{p}<0.05)$; and conflicts with pedestrians $(\beta=1.173, \mathrm{p}<0.05)$. Similarly, (Okon \& Moreno, 2019) filmed segments for 20-40 seconds during bicycle rides at a speed of about $5 \mathrm{~km} / \mathrm{h}$ with a camera strapped, at an angle of 45 degrees, on the head, which was subsequently rated by respondents. Curb lane variables such as bicycle pathway widths, curb lane motorized volume $(\mathrm{veh} / \mathrm{h})$ and vehicle speed $(\mathrm{km} / \mathrm{h})$, bicycle volume on the segment, and median width was recorded in addition to secondary data. The study observed that BLOS was strongly influenced by side path separation, vehicle speed, motorized traffic volume and conflicts with pedestrians. A few other studies such as those (Ghodrat-Abadi \& Hurwitz, 2018) had their BLOS indices including lane markings on the network or speed bumps (Vasudevan \& Patel, 2017; Mertens, et al., 2016) leading to deviations and queuing with the likely outcome of smoot flow of traffic and thus higher safety levels (Hourdos, et al., 2017; Pokorny \& Pitera, 2019).

In assessing bicyclist comfort level in Minneapolis, Minnesota Krizek and Roland (2005) collected data on 30 identified bicycle lanes with discontinuities. These primary data were obtained from the measurement of physical attributes of bicycle and motorized infrastructure and cyclists' perception of satisfaction. Multivariate analysis including the ordinary least squares method was used to analyse data, leading to the formulation of his model. These comfort levels can be addressed through widening the bicycle lane (Chen, Yue \& Han, 2018), cyclists' manoeuvres abilities (Mohammed \& Bigazzi, 2018), e-bike navigation behaviours (Kazemzadeh, Laureshyn, Ronchi, Agostino \& Hiselius, 2020), which according to Fishman and Cherry (2016) remains the fastest growing means of transportation with an average speed of $16.9 \mathrm{~km} / \mathrm{h}$ (Dozza, Piccinini \& Werneke, 2016; Schleinitz, Petzoldt, Franke-Bartoldt, Krems \& Gehlert, 2017), among others. Few studies that examined the challenges posed by pedestrians on cyclists and e-bike users alike also exists (Bai, 
Liu, Liang, Chan \& Yu, 2017). Where on-street bike lanes are provided, Pu, Li, Wang, Ye and Fan (2017) observed that a large volume of cyclists infiltrating into vehicle lanes often compromises cyclists' comfort and safety.

The Bicycle Intersection Safety Index (ISI) model was developed to provide insight into the ability of transportation planners to evaluate the level of safety in intersections. It was carried out in North Carolina and its methodology was based on the use of video data and an online safety rating survey of 67 intersection approaches. The study used variables that indicated a high probability of risk by bicyclists such as 'traffic volume, the number of lanes, the speed limit, the presence of a bike lane, the presence of parking and the presence of traffic control. The rating for an intersection approach is accordingly based on a six-point scale (Carter, Hunter, Zegeer, Stewart, \& Huang, 2007). In terms of bicycle lanes, Greibe and Buch (2016) analysed the capacity and behaviour of one-way bike paths with different widths in Denmark where it was concluded among other things that 'width does not affect the capacity except when there is an increasing or decreasing number of lanes'. Similarly, (Ye, Yan, Chen, Wang and Sheng (2018) employed the proportion of e-bikes, lane width and influence of parking manoeuvres as indicators for actual capacity of the bike lane, while Liang, Xie and Jia (2018) observed that bike path width directly impacts path capacity.

Several strategies have been adopted by different metropolitan administrators aimed at promoting cycling in cities such as lane separation (Sanders, 2016), on-street and off-street facilities (Liang, Xie \& Jia, 2017), or mid-block bicycle lanes on urban streets (Bai, Liu, Chan \& Li, 2017). Others implement different enforcement policies in traffic lights systems (Lu, Blokpoel \& Joueiai, 2018; De Angelis, et al., 2019). Sixty (60) participants of a real-time roadway bicycle course responded to safety at signalized and un-signalized intersections in Florida, USA (Landis, Vattikuti, Ottenberg, Petritsch, Guttenplan, \& Crider, 2003). Pearson Product Moment Correlation was used to analyse about 1000 combined real-time responses from participants to formulate the intersection. The study, therefore, concluded that 'roadway traffic volume, the total width of outside through lane, and intersection crossing distance' remained important considerations for planning bicyclist safety at intersections.

However, essential data and generally accepted methodologies for measuring the use of these intersections for bicyclists are unavailable for planning and management purposes. It is therefore difficult to achieve an evidence-based choice among investment alternatives and to optimize management of infrastructure and transportation systems due largely to lack of data and necessary tools for estimating facility use. Transportation planners and engineers alike need information and scientific tools for estimating bicycle traffic volume and pattern of facility use. The theme of this research therefore emerged to evaluate the level of satisfaction of bicyclists at intersections thereby developing suitable indicators that helps policy makers prioritize their investments in new and existing bicycle infrastructures. Relevant segments of the bicycle road network can thus be improved or redesigned especially in terms of intersection to enhance the capability of cycling paths. The methodology can be used to promote cycling use through infrastructure audits especially in developing countries and thus set up further discussion on what variables can be used to address location-specific cycling challenges.

\section{METHODOLOGY}

Two reconnaissance surveys were carried out in Enschede and Bogota to test for our data collection equipment and ascertain the validity, and operational feasibility of our methodology. Different layers of data were used in this study such as perceptions rating data for intersections, geometric, physical and operational characteristics of road infrastructure based on both measurement and observation data.

\section{Video production/editing}

Intersection videos were produced at different times/days of the week. Some sampling criteria include land use characteristics, trails, ciclocarrils and ciclovia (Sunday cycling). For every intersection, about 3-5 videotapes were made. Intersections were separately filmed for 20-40 seconds while riding a bicycle at a speed of about $5-10 \mathrm{~km} / \mathrm{h}$ using a camera strapped 45 degrees on the head (see figure 1). In principle, therefore a maximum of three videos can be produced in any route to reflect three kinds of intersections (that is, intersection connecting three, four or multiple roads). Only one of each intersection category was examined along a chosen route. Weighting is used for others of the same class and multiplied by the number in that type, which is used in the survey after editing.

During editing, videos were reduced to between 10-16 seconds and an instant 'repeat mode' of the same time to allow review by participants. All intersections were also appropriately named at the beginning of each video and a 5 seconds break was introduced between intervals of successive videos.

\section{Video production/editing}

The scope of this study does not allow for a complete video-taping of all intersections of the cicloruta. Secondly, survey participants couldn't view and rate all intersections due to lack of time and fatigue associated with lengthy videotapes. The choice of the intersection was much more complicated as there are different categories. However, for easy assessment and possible aggregation, the number of intersections in each route was identified and categorized according to three-leg (T-leg), four-leg and multiple legs intersections (Table 1) (DelDOT, 2011). Additional criteria for sampled intersections choice include: 
a. Width, signalized and un-signalized.

b. Economic efficiency of the design and number of levels and streams.

c. The shape of surrounding terrain and situation of intersection within the alignment.

d. Traffic canalization methods and management.

e. Allowed crossing, travelling and methods of transportation of cyclists.

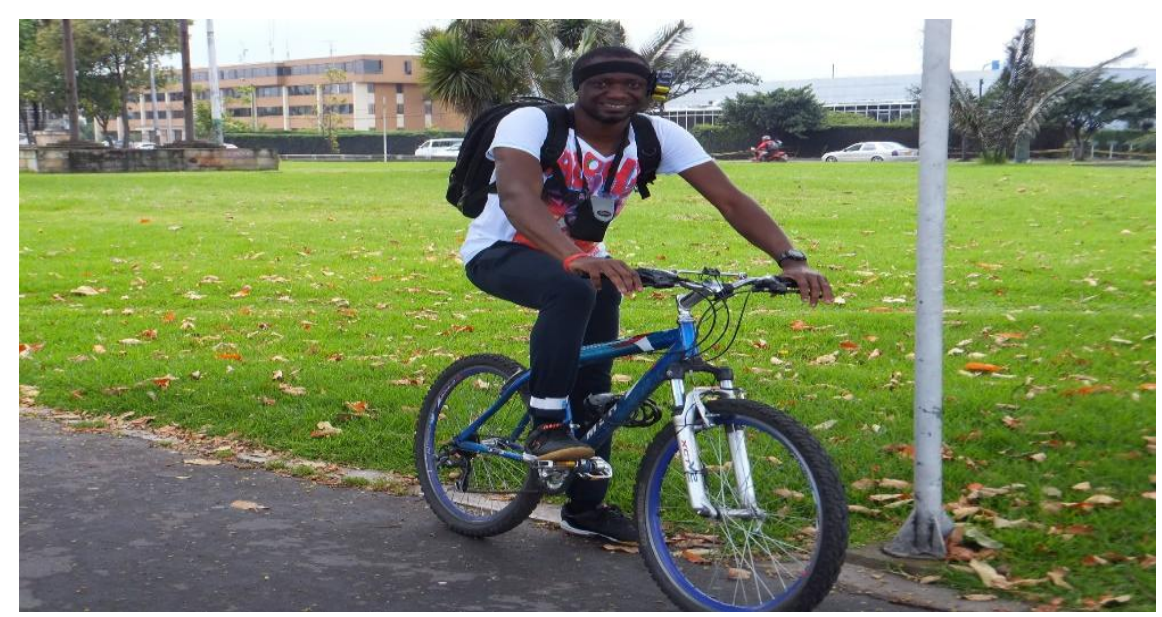

Figure 1: Display of camera position as used by the author during field survey

Source: Author's field survey, 2021

The choice of intersection for LOS estimation is critical for an unbiased estimation. Previous studies whose efforts were based on existing data fall short of this as the choice of location for such data may be subjective. For example, data from advocacy groups, municipal authorities, transport agencies, communities, all reflect mostly areas with high volume with reported problems while other areas of relatively low volumes with minimal challenges are neglected. Since it is not possible to investigate all intersections within a limited study scope, typology of the intersection was adopted in our choice. These include Three-leg or T-intersection; four-leg intersection; and multi-leg intersection (as mentioned earlier). In addition to this stated criterion, the selection was also made to reflect other transport characteristics as cyclist volume, diversity in land use, transportation characteristics and infrastructure as well as neighbourhood socioeconomic characteristics. Given the network characteristics of the study area, 8 intersections were sampled to reflect 3 legs, 4 legs and multiple legs and other geometric and physical characteristics (figure 2). The strategic process employed in the selection of intersections for the model estimation includes, identify from relevant road maps and field observations the number of segments as a measure of intersections in the transport corridor.

Table 1: Distribution of intersections in the study area

\begin{tabular}{lcc}
\hline S/no & Intersection & Description \\
\hline 1 & Carrera 19xCalle 13 & 3legs \\
2 & Carrera 13xCalle 51 & 4 legs \\
3 & Carrera 24xCalle 53 & 4legs \\
4 & Carrera 80xCalle 38c & Multiple legs \\
5 & Carrera 13xCalle 34 & 4legs \\
6 & Carrera 13xCalle 54 & Multiple legs \\
7 & Carrera 7xCalle 19 & Multiple legs \\
8 & Carrera 71dxCalle 3s & 3legs \\
\hline
\end{tabular}

Source: Author's field survey, 2021

Therefore, the following variables were shown on the video clip to participants: bicycle facilities on approaches; bicyclist positioning on approaches; sight distance; the number of driveways on main streets; pavement conditions; bicycle signals; motorized traffic control; motorized traffic speed; the number of lanes; the number of total intersection legs; one-way or two-way roadway being crossed; street lighting; crossing width; motorized traffic volume (rightturning); and motorized traffic volume (left-turning from the opposite direction).

All intersections were also appropriately named at the beginning of each video and a 5 seconds break was introduced between intervals of successive videotapes to separate each video from another. Eight (8) videos constitute data for intersections videos and rating sheets used in the survey were translated to Spanish to enhance effective participation. Viewing of intersection videos takes about 3 minutes. The first section on socio-economy and experience of cyclists was estimated to take about 5 minutes, making a total survey time of 8 minutes. The author believes this served as motivation 
for participation in the survey. Earlier studies used staff as participants (Landis, 1996) or some free cinema tickets to motivate participants (Jensen, 2007).

\subsection{Intersection LOS variables}

Volume of cyclists (VOC)

The scope of study makes it difficult for data to be collected for 15 minutes per intersection. The very nature of some neighbourhoods with safety issues and complicated network systems further compounds this challenge. However, observation from video clips is used to obtain data on the volume of cyclists that crosses an intersection at survey time. Since the author had 3 or more fieldwork assistants, the same assumption was applied in deciding volume. A score of 1 is assigned to an intersection if 2 or more cyclists are crossing (excluding team members) at the time of the survey, 0 otherwise.

\section{Conflicts with pedestrian/cyclists (CPC)}

Conflicts with other cyclists, pedestrians and other wheeled tricycles impede cyclist's ability to cross intersections and thus affect their satisfaction. Videotapes from field observations reveal this as a problem in Bogota. The study, therefore, considers a value of 1 for $\geq 3$ conflicts, 0 otherwise. This data is observed from collected video clips.
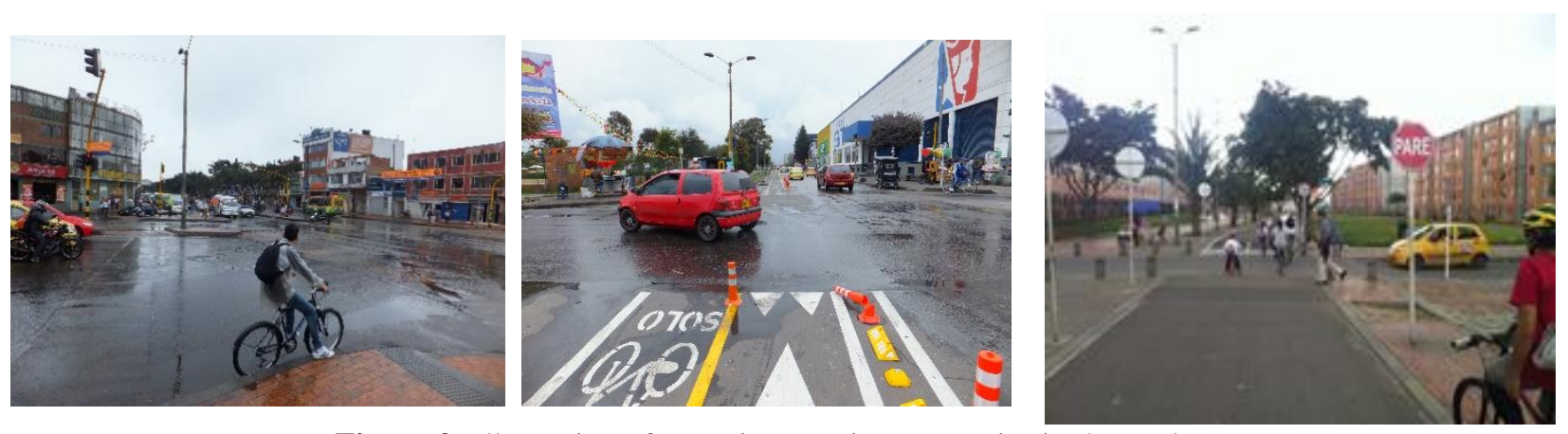

Figure 2: Illustration of some intersection categories in the study area

Source: Author's field survey, 2021

\section{Safety and risk (SAR)}

However subjective this factor may seem; it is thus an issue that affects bicycle use in Bogota. Data on security was difficult to assess, but an oral interview with some residents reveal great risk and safety concerns mostly in the southern part of the city. The variable would not be considered separately for lack of data, more so that it has been considered by participants during rating.

\section{Road signs and markings (RSM)}

Road signs and markings inform bicyclists, pedestrians, and motorists alike on their rights, the absence of which generate user conflicts resulting in accidents and a thus deteriorating level of satisfaction. The study assigns a score of 1 for clear road/traffic signs and markings, 0 otherwise.

\section{Total intersection legs (TIL)}

The number of intersection legs has a relationship with the width of crossing, though they may be few exceptions, thus the level of service of that road infrastructure. If the intersection has 3 legs, 1 is assigned, 0 otherwise.

\section{Crossing width of intersection (CWI)}

The very nature of the lack of special design to accommodate bicyclists at the intersection makes its width an influential factor in the level of satisfaction. Intersections with $\leq 12$ feet are assigned 1,0 otherwise.

Other useful variables such as motorized traffic volume (right turning and left turning in the opposite direction) prove to be a useful variable in intersection studies (Landis, 1996). This could not be included in the survey due to the limited scope for this study and the enormous number of intersections in the study area. This notwithstanding, it is expected that other variables proved adequate to estimate our model. A comprehensive variable description for intersections was attempted in Table 2. It thus includes perception ratings as well as other geometry, physical and operational characteristics of the Bogota transport system. It forms the basis of analysis at all levels of LOS estimation using the prescribed methods.

\section{Data analysis technique}

The LOS model is a macroscopic model which has the relationship between space, walking speed and flow. Different methods exist in the literature on how inputs into the model can be solved to generate LOS. Logit regression analysis of 
non-motorized commuting was used in the United States to predict the specific form of NMT commuting such as working at home, walking to work and cycling to work (Plaut, 2005). The ordinary generalized linear models (GLMs), cumulative logit models (CLMs), and ordinary probit models (OPMs) were used [19] to develop bicycle and pedestrian

Table 2: Variable description

\begin{tabular}{|c|c|}
\hline Variable & Variable description \\
\hline $\begin{array}{l}\text { Dependent } \\
\text { variable }\end{array}$ & $\begin{array}{l}\text { Perceived satisfaction rating of the cicloruta (for the segment and intersection surveys) } \\
\text { based on six-point Likert ranging from } 1 \text { as highly satisfied to } 6 \text { as highly dissatisfied }\end{array}$ \\
\hline $\begin{array}{l}\text { Respondents' } \\
\text { demographics }\end{array}$ & $\begin{array}{l}\text { Gender }(1=\text { Male; } 0=\text { Female }) \text { Age }(1=\geq 35 ; 0=>36) \\
\text { Localidad }(1=\text { Barrios Unidos; } 2=\text { Teusaquillo; } 3=\text { Puente Aranda; } 4=\text { Los Martires; } \\
5=\text { Antonio Narino; } 6=\text { Tunjuelito; } 7=\text { Rafael Uribe; } 8=\text { Candelaria; } 9=\text { Santa Fe; } 10=\text { Suba; } \\
\text { 11=Usaquen; } 12=\text { Chapinero; } 13=\text { Kennedy; } 14=\text { Engativa; } 15=\text { Fontibon; } 16=\text { Bosa; } 17=\text { San } \\
\text { Christobal; } 18=\text { Usme; } 19=\text { Sumapaz; } 20=\text { Cuidad Bolivar }) \\
\text { Housing type (5=Detached; } 6=\text { Terraced; } 7=\text { Flat; } 8=\text { Student hostel; } 9=\text { Other }) \\
\text { Bicycle ride in Bogota city }(1=\text { Yes; } 0=\text { No) } \\
\text { Number of bicycle trips undertaken }(1=<5 ; 2=5-10 ; 3=10+) \\
\text { Number of km/week with bike }(5=<10 ; 6=10-15 ; 7=16-29 ; 8=30-45 ; 9=46+)\end{array}$ \\
\hline $\begin{array}{l}\text { Riding } \\
\text { experience }\end{array}$ & $\begin{array}{l}\text { Experience in riding }(1=\text { Experienced; } 0=\text { Inexperienced }) \\
\text { If yes, how many km do you ride to work/school; shopping; recreation; and other? } \\
\text { What percentage of your riding is done in major roads; residential streets; cicloruta; } \\
\text { sidewalks; and other road facilities? }\end{array}$ \\
\hline $\begin{array}{l}\text { Environmental } \\
\text { conditions }\end{array}$ & $\begin{array}{l}\text { Does the weather affect your decision to use the bike? }(1=\text { Yes; } 0=\mathrm{No}) \\
\text { If yes; rain; drizzle; steady rain; heavy rain; fog; hot weather }(1=\text { Yes; } 0=\mathrm{No})\end{array}$ \\
\hline $\begin{array}{l}\text { Intersection } \\
\text { variables }\end{array}$ & $\begin{array}{l}\text { Volume of cyclists (VOC): } 1=\geq 2 \text { cyclists; } 0=\text { otherwise } \\
\text { Conflicts with pedestrian/cyclists (CPC): } 1=\leq 3 \text { conflicts } \\
\text { Road signs and markings (RSM): } 1=\text { signs/markings present; } 0=\text { otherwise } \\
\text { Total intersection legs (TIL: } 1=31 \text { eg; } 0=\text { otherwise } \\
\text { Crossing width of intersection (CWI): } 1 \leq 12 \mathrm{ft} ; 0=\text { otherwise }\end{array}$ \\
\hline
\end{tabular}

Source: Author's field survey, 2021

models in his Copenhagen study. On the other hand, Hankey, Lindsey, Wang, Borah, Hoff, Utecht and Xu (2012) employed both ordinary least square (OLS) and maximum likelihood estimation (MLE) of the regression statistics to estimate models of bicycle and pedestrian traffic in Minneapolis. Pearson correlation analysis was used to estimate models and predict pedestrian LOS in Landis, Vattikuti, Ottenberg, McLeod, and Guttenplan (2001) study of 'modelling the roadside walking environment: pedestrian level of service' in Pensacola, Florida. In developing pedestrian level of service for sidewalk, Tan, Wang, Lu and Bian (2007) applied Pearson correlation coefficient to measure linearity between variables of interest to obtain coefficients which are used in their model. Similarly, Provide and da Penha Sanches (2011) used the method of the successive interval to define traffic characteristics based on the priority of users and potential users to evaluate bicycle infrastructure in Brazilian medium-sized cities. These studies and much more formed the background for our statistical techniques whose assumptions are met by our data set.

In other to evaluate the level of satisfaction of bicyclists in the study area, a statistical method with the capabilities for choice ordered modelling involving ordered discrete data of the form A-F was needed. Multinomial logit model from the traditional multinomial discrete-outcome models is however a possibility but reveals a weakness in their inability to order the nature of data. In other words, A is better than B; B is better than C; C is better than D; and so on, and therefore may result in loss of efficiency in parameter estimation according to (Amemiya, 1985). Other possibilities include models for binary outcomes and other exponential distributions such as Poisson, negative binomial and so on (Nelder \& Wedderburn, 1972). However, ordered probability method is appropriate for modelling choice and by extension satisfaction Greene \& Hensher, 2010; Washington, Karlaftis, \& Mannering, 2011). Using the Genlin procedure in SPSS, ordered probit logit were fitted in the generalized linear models (GLMs), as this allows the fitting of ordinal outcomes, such as perception of LOS as rated by our survey participants based on video experiment. It is an extension of ordinal least-squares regression that generalizes linear regression and thus allows the linear model to be related to the response or dependent variable (in our case the overall rating of segments/intersection). It is a multinomial probability distribution with cumulative logit as link function (Okon, et al., 2017; Okon \& Moreno, 2019).

\section{RESULTS/FINDINGS}

In other to have an estimation that more readily reflect true bicycle transport conditions in Bogota, the study examined the impact of intersection on ciclorutas. Some studies that estimated bicycle level of service exists ( $\underline{\mathrm{Carter}}$, et. al, 2003; Dowling, 1994; Landis, et. al, 2003; Zhang \& Prevedouros, 2003). Not many studies have considered joint estimation of intersection and segment. Carter et al (2007) developed an intersection safety index for North Carolina using the generalized linear models, while Landis et al., 2003 developed a methodology for estimating intersection level of service for the Florida Department of Transportation (FDOT) using Pearson correlation and factor analysis. 
Three classes of intersection were identified where average LOS for multiple, 4 and 3legs intersections included in Table 3. The intersection level of service rating of participants shows that the average satisfaction of intersections is low. This however suggests that an average intersection in the study area possess similar challenges to cyclists whereas safety and security levels may vary across different neighbourhoods. Figure 3 presents a graphic illustration of some of these intersections and their accompanying average perception LOS scores compared to the Highway Capacity Manual (2000) values in Table 4. Field observations also revealed that some segments were not defined necessarily by intersection but by other factors such as a complete cycle of the trail, termination of constructed cicloruta, and so on. The result may not be unconnected with the fact that the survey was mostly during the peak period and the level of dissatisfaction that participants already have about intersections before the survey. Based on our video survey and extrapolation of data across the study area we thus obtain our perception BLOS. This enables us to substitute satisfaction levels in the equation to estimate our BLOS.

\section{Estimation results of intersection BLOS model}

About 680 perceptions of satisfaction ratings from 85 participants were used in the estimation of this model. Other geometry, physical and traffic operational characteristics were also used. They included the volume of cyclists, conflicts with other cyclists and pedestrians at intersections, road signs/markings at intersections, total intersection legs, and crossing width of intersections (Table 5). Experience and bicycle ridership in the city by participants were used as covariates in the estimation process. An insignificant difference in deviance and Pearson Chi-Square (0.044) and Loglikelihood chi-square of .000 suggests that our model provides a better fit of the data. Therefore, based on the significance level of our variables, the selection is made of those with statistically superior contributions to our model and thus estimates are derived (box 1).

Since the level of experience is subjective based on feeling and understanding of the question on this variable, it was decided to exclude it from the model just as gender was used as a covariate, even though they were statistically

Table 3: Average score of sample lane intersections of the cicloruta

\begin{tabular}{lllllll}
\hline s/n & Sampled intersection & Ave. score & Class & Class ave. & \% & Description \\
\hline 1 & Carrera 80 by Calle 38c (M-L) & 4.16 & 3 & 4.64 & 37.5 & MD \\
2 & Carrera 7 by Calle 19 (M-L) & 4.2 & 3 & 4.64 & 37.5 & MD \\
3 & Carrera 71d by Calle 3s (M-L) & 4.21 & 3 & 4.64 & 37.5 & MD \\
4 & Carrera 13 by Calle 54 (4-L) & 4.47 & 4 & 4.50 & 37.5 & MD \\
5 & Carrera 13 by Calle 34 (4-L) & 4.52 & 4 & 4.50 & 37.5 & MD \\
6 & Carrera 24 by Calle 53 (4-L) & 4.65 & 4 & 4.50 & 37.5 & MD \\
7 & Carrera 13 by Calle 51 (T-L) & 4.88 & 5 & 4.44 & 25 & MD \\
8 & Carrera 19 by Calle 13 (T-L) & 4.0 & 5 & 4.44 & 25 & MD \\
\hline
\end{tabular}

MD = Moderately Dissatisfied

Source: Author's field survey, 2021

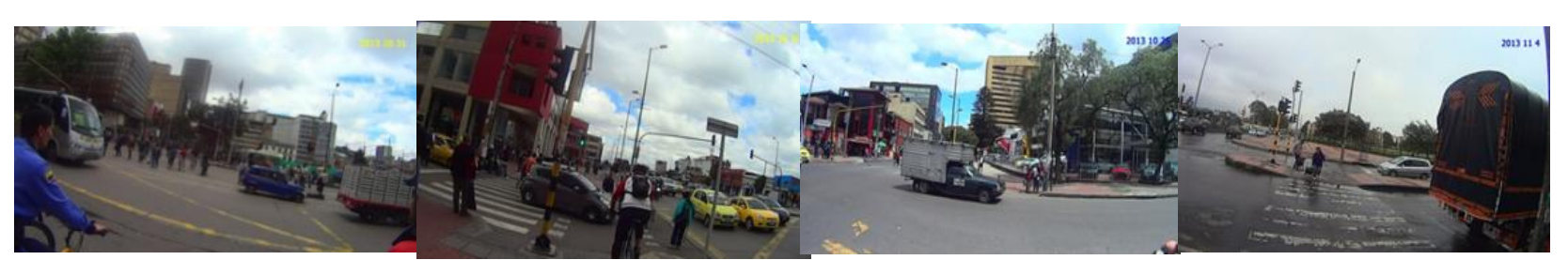

Figure 3: Sampled intersections in Carrera 7 x Calle 19 (4-lane) (LOS=4.2); Carrera 19 x Calle 13 (LOS=4.9); Carrera $13 \times$ Calle $34(\operatorname{LOS}=4.5)$; and Carrera $80 \times$ Calle $38 \mathrm{c}(\operatorname{LOS}=4.2)$

Source: Author's field survey, 2021

Table 4: LOS scores (after HCM, 2000)

\begin{tabular}{lll}
\hline LOS & Score & Description \\
\hline A & $\leq 2.00$ & Excellent \\
B & $>2.00-2.75$ & Very good \\
C & $>2.75-3.50$ & Good \\
D & $>3.50-4.25$ & Fair \\
E & $>4.25-5.00$ & Poor \\
F & $>5.00$ & Very poor \\
\hline
\end{tabular}

Source: Author's field survey, 2021 
Significant at a confidence interval of 0.05 . It has been earlier observed that perception intersection BLOS is ' $E$ ' for all three kinds of intersections (Table 3). The model in box 1 is used in ArcGIS to demonstrate the estimation of intersection BLOS. Earlier results of parameter estimates (Table 5) reveal three variables as making a superior contribution to the model using a 0.05 level of significance. They include the volume of cyclists, conflicts with pedestrians and other cyclists; and total intersection legs.

The volume of cyclists was observed measurement of the number of other cyclists crossing in the same direction during field data collection. No specific consideration was given to either peak or off-peak, however, data were collected during all traffic periods. Where 2 or more cyclists cross an intersection, a value of 1 is assigned since this is seen as a measure of safety feeling, and zero when only one cyclist crosses at a given time. This time is called the 'effective green time to signal cycle length ratio' defined as 'composed of the sum of the time of the green $(\mathrm{G})$, yellow (Y) and all red (R) ball signal indications minus the sum of the start-up and clearance lost times' times' (Zhang \& Prevedouros, 2003). The collection of this data was subjective to the extent of the scope of this research while future

Table 5: Random parameters ordered probit model of bicyclists perceived LOS (intersections)

\begin{tabular}{|c|c|c|c|c|}
\hline Variable description & $\begin{array}{l}\text { B } \\
\text { (Parameter est.) }\end{array}$ & $\begin{array}{l}\operatorname{Exp} B \\
\text { (Variance of est.) }\end{array}$ & $\begin{array}{l}\text { Wald Chi- } \\
\text { Square }\end{array}$ & Sig. \\
\hline Threshold 1 & -2.960 & 0.052 & 53.719 & .000 \\
\hline Threshold 2 & -1.568 & 0.209 & 39.848 & .000 \\
\hline Threshold 3 & -0.680 & 0.506 & 8.110 & .004 \\
\hline Threshold 4 & 0.017 & 1.017 & 0.005 & .944 \\
\hline Threshold 5 & 0.792 & 2.208 & 10.955 & .001 \\
\hline Threshold 6 & 2.024 & 7.565 & 65.240 & .000 \\
\hline $\operatorname{VOC}(1=\geq 2$ cyclists crossing; $0=$ otherwise $)$ & 1.116 & 3.053 & 46.354 & .000 \\
\hline $\mathrm{CPC}(1=\leq 3 ; 0=$ otherwise $)$ & 1.048 & 2.851 & 59.851 & .000 \\
\hline RSM ( $1=$ RSM present; $0=$ otherwise $)$ & 0.079 & 1.082 & 0.123 & .726 \\
\hline TIL ( $1=3$ legs; $0=$ otherwise) & -0.365 & 0.694 & 5.221 & .022 \\
\hline CWI ( $1=\leq 12$ feet; $0=$ otherwise $)$ & -0.111 & 0.895 & 0.291 & .590 \\
\hline Experience $(1=$ Yes; $0=$ otherwise $)$ & -0.465 & 0.628 & 25.934 & .000 \\
\hline Ride ( $1=$ Ride in the city; $0=$ otherwise) & 0.160 & 1.174 & 3.293 & .070 \\
\hline Age & 0.022 & 1.022 & 0.033 & .856 \\
\hline Gender ( $1=$ Male; $0=$ Female $)$ & -0.534 & 0.586 & 38.093 & .000 \\
\hline Number of observations & 860 & & & \\
\hline Log-likelihood chi-square & $131.619(.000)$ & & & \\
\hline Deviance & $371.496(.820)$ & & & \\
\hline Scaled Deviance & 371.496 & & & \\
\hline Pearson Chi-Square & $351.348(.776)$ & & & \\
\hline Scaled Pearson Chi-Square & 351.348 & & & \\
\hline Log-likelihood & -363.679 & & & \\
\hline Akaike’s Information Criteria (AIC) & 757.358 & & & \\
\hline Finite Sample Corrected AIC (AICC) & 758.081 & & & \\
\hline Bayesian Information Criteria (BIC) & 825.189 & & & \\
\hline Consistent AIC (CAIC) & & & & \\
\hline
\end{tabular}

Dependent variable responses are integers ranging from 1-6 for A-F (highly satisfied-highly-dissatisfied)

Source: Author's field survey, 2021

Research can measure all effective green time at every signalized intersection.

Conflicts with other cyclists and pedestrian is also an observed data collected as author and field assistants rode across different segments and intersection of the network. Several conflicts were observed at many intersections around the CBD and other high-density residential areas in the south. Based on the author's experience, therefore, a value of 1 is coded to conflicts of 3 or less and zero if more than 3 . Whereas the presence of more cyclists may increase the feeling of safety amongst cyclists, crossing an intersection in opposite direction with pedestrians and cyclists alike causes a lot of accidents and thus dissatisfaction.

Total intersection legs are a measure of the number of through lanes in an intersection. It also correlates strongly with the width of the intersection. It was statistically more superior in its contribution than crossing width itself perhaps due to the nature of intersection design in Bogota ( $\underline{\mathrm{HCM}}, 2000)$. The design does not incorporate cycling around a roundabout to adjoining segment, rather the use of the pedestrian cross over (HCM, 2000). Where an intersection has three crossing legs (T-junction), we assign a value of 1 , otherwise zero. This to an extent is subjective as data was collected from observation and relevant street maps. It was difficult to define which intersection is 3 , 4 or multiple legs since all motorized and non-motorized modes affect cycling. 
Box 1: Bicycle level of service for the cicloruta intersection

BLOS $_{\text {intersection }}=\left\{\begin{array}{c}\mathrm{HS}=-2.960 \\ \mathrm{MS}=-1.568 \\ \mathrm{AS}=-0.680 \\ \mathrm{AD}=0.017 \\ \mathrm{MD}=0.792 \\ \mathrm{HD}=2.024\end{array}\right\}+1.116 . \mathrm{VOC}+1.048 . \mathrm{CPC}-0.365 . \mathbf{T I L}$
where:
VOC = volume of cyclists; CPC = conflicts with pedestrian and other cyclists; and
TIL = total intersection legs;
$\mathrm{HS}, \mathrm{MS}, \mathrm{AS}, \mathrm{AD}, \mathrm{MD}$, and HD are as previously defined.

Source: Author's field survey, 2021

Validation of our methodology involved the sampling of 33 intersections from 3 ciclorutas (Las Aquas-Av El Dorado, Avenida Boyoca, and Avenida Ciudad De Cali). The model in box 1 was then used in ArcGIS to estimate both intersection BLOS and facility BLOS by equations (1) and (2):

AVBLOSsegment $=\sum$ BLOSsegment $1+2, \ldots, n, \mathrm{n}$

where AVBLOSsegment $=$ average BLOS score for cicloruta sharing similar name ID; $n=$ referring to nth number of ciclorutas; and $N=$ total number of segments.

BLOSfacility $=\left(\sum\right.$ BLOSsegment $+\sum$ BLOSintersection $) / 2$

$\mathrm{n}$

where:

BLOSfacility is bicycle level of service score at facility level (defined as all cicloruta sharing similar name identity irrespective of their categorisation;

$\sum B L O S s e g m e n t$ is bicycle level of service score at segment level;

$n$ is the number of segments in that facility; and

$\sum B L O$ Sintersection is bicycle level of service score at intersection level.

Model limitations and applicability

Average intersection scores for all three sampled ciclorutas included 2.93, 3.09, and 3.18 respectively. The effectiveness of this methodology is expressed in figure 4 with sampled segments showing the level of satisfaction derived from use of every intersection across a given path. The second map in the figure reveals the BLOS score at the facility level. This is given as average BLOS plus Average intersection BLOS divided by two (equation 2).

Some methodologies in the past had combined right turn through traffic and left turn opposite traffic as well as other variables like the specific design of intersections and length of segments between intersections. The scope of this study could not consider these variables in the model since some operational variables are already considered in segment BLOS.

The aggregation of participant's 680 perceptions of satisfaction ratings may not necessarily reflect actual perception levels across the study area. This is because of the small sample size which the scope of this study accommodates. Further studies may validate the perception of bicyclists using larger sample sizes to examine levels of satisfaction. The sample size of participants comprising over 70 per cent of students and 80 per cent of $>35$ years of overall age of participants tends to influence satisfaction level as many studies have posited.

The ordered probit model as used in this study captures the heterogeneity between individual participants and their perception of satisfaction. This data is limited to Bogota and cannot be copiously applied elsewhere, except with modifications to reflect local transportation circumstances. The choice of a six-point rating scale is due to the LOS measurement earlier developed by Landis (1994) and modified by the Highway Capacity Manual (2000) as one of the most acceptable standards for comparing satisfaction levels. It cannot completely be said to be advantageous as Kang et al., 2006 (, has proved when they developed a three-point rating scale for bicycle level of satisfaction. Avenida Boyoca with an AvBLOS score of 3.3492 has BLOSfacility of 3.2202 equivalents to grade ' $\mathrm{C}$. Avenida Ciudad De Cali on the other hand with 2.33 AvBLOS has 2.7529 BLOSfacility or ' $C$ ' grade. This indicates the weakness of the grading system as this cicloruta is only 0.0529 points away from its earlier ' $\mathrm{B}$ ' grade. Moreover, Las Aquas-Av El Eorado also scored ' $\mathrm{C}$ ' grade or 2.7616 BLOSfacility from its earlier AvBLOS score of 2.5907 (figures 4 and 5). 
These limitations notwithstanding, the study has provided an empirical methodology for estimating the level of satisfaction that bicyclists derive from the use of the cicloruta, and by extension made a contribution to the existing body of literature on the subject matter. The methodology is suitable for application in many countries with modifications on the scoring of variables. The findings confirm the validity of the use of video data in combination with other geometry, physical and operational traffic characteristics as opposed to Epperson (1994) suggestion that video simulation alone can be used to simulate LOS models. It has however confirmed to be effective in view of the complex nature of intersections in the study area, whose design is considered not safe for cycling in many parts of the city.
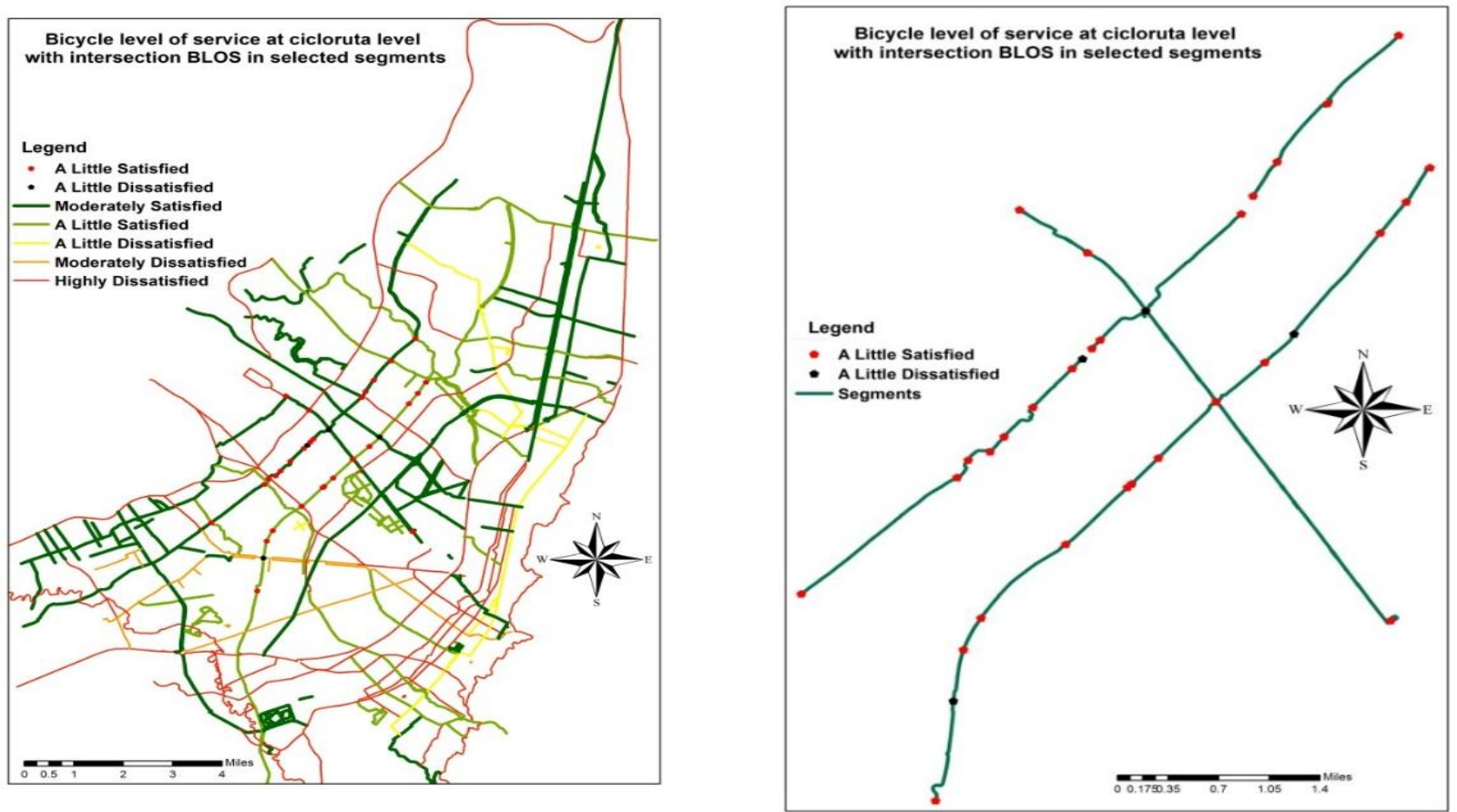

Figure 4: Intersection BLOS in cicloruta network and at segment level

Source: Author's field survey, 2021
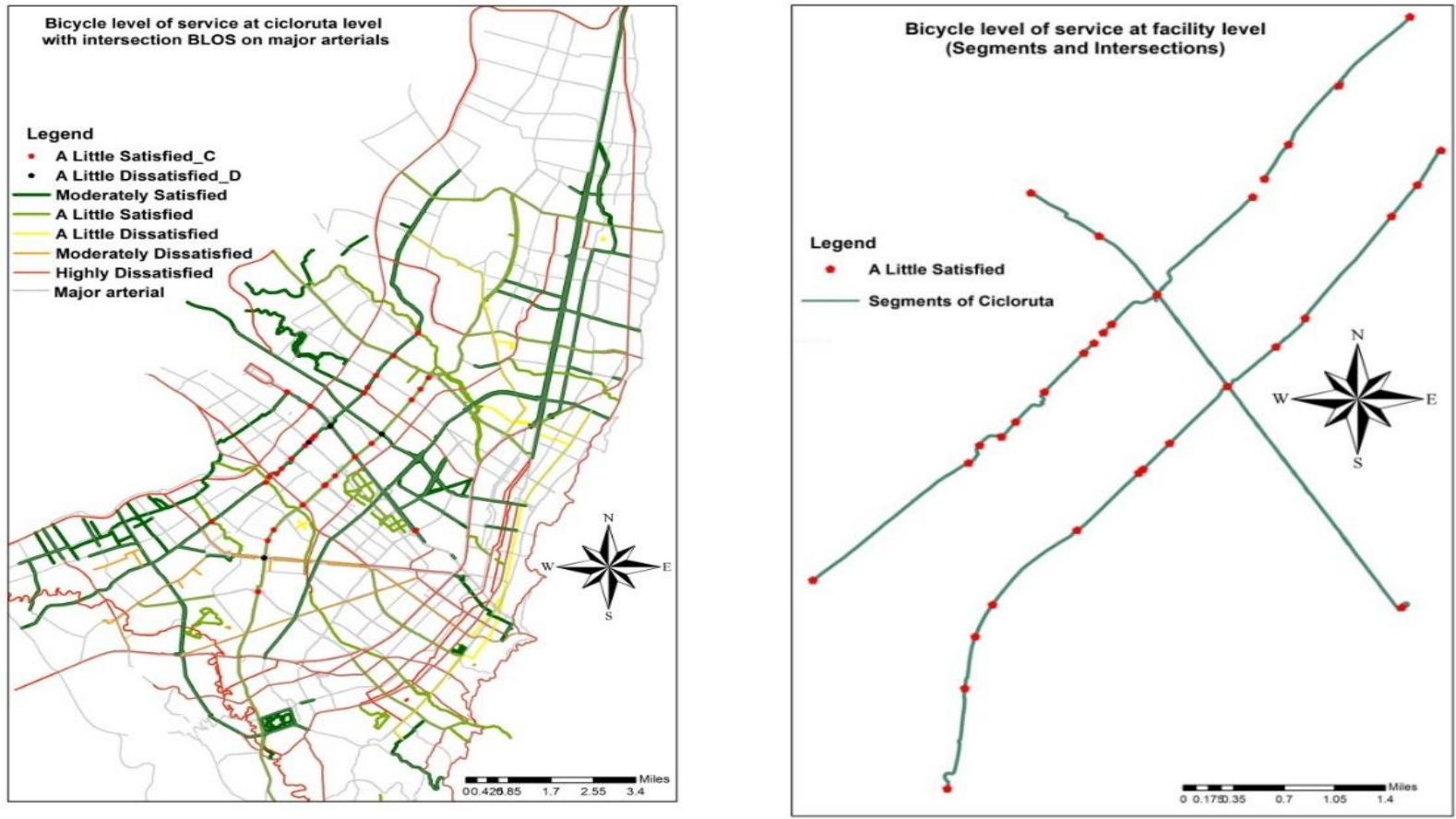

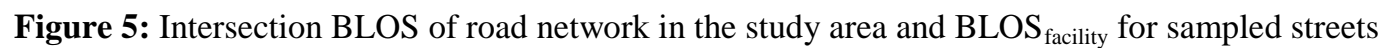

Source: Author's field survey, 2021 


\section{CONCLUSION}

The proposed model, therefore, represents an intersection BLOS methodology for evaluating bicycle infrastructure in Bogota providing an alternative solution that seeks encouragement for cycling mode of transport. It is however believed that this model would be useful not only in Bogota but also in South America and indeed elsewhere in the world as an effective tool for bicycle infrastructure planning. An expansion and further improvements are possible to reflect peculiar transport circumstances of different cities in both developed and developing countries. Further testing for the significance of model variables such as side path separation, vehicle speed, motorised traffic volume and conflicts with a pedestrian is also possible. The output of this research can become vital components of data for routing of ciclorutas along slope, best route and shortest path along good ciclorutas and so on. Future studies would have to enlarge the scope of this study to fully understand the satisfaction level of cyclists and potential users on the quality of infrastructure for bicycling. Other methods that seek to focus on the different profiles of bicyclists are recommended. However, based on the methodology and result of this research, a redesign of the intersections is inevitable for enhancing sustainable cycling in Bogota.

\section{LIMITATION AND STUDY FORWARD}

The study has successfully estimated the model using different data levels to provide an empirical methodology for the level of satisfaction that bicyclists derive from the use of the cicloruta, and by extension contributed the knowledge on this subject. The method is suitable for application in many countries with modifications on the scoring of variables. The successful estimation of these models notwithstanding, the methodology exhibits some weakness in its inability to rigorously define bicyclists' intersection level of satisfaction which suggests that perception of satisfaction would vary considerably across all participants. This model does not incorporate crash data in its estimation which is observed to have related strongly with BLOS performance evaluation as shown in the Gainesville study which shows that accidents are concentrated at congested central, commercial or high activity centres. Further studies are therefore recommended in this respect as well as modelling accessibility through different scenarios of LOS in Bogota.

\section{ACKNOWLEDGEMENTS}

The contribution of staff/management of Humana Bogota, Instituto de Desarrollo Urbano (IDU), IDECA, Piloto University, Los Andes University, Rosario University, Despacio and Movilidad is well acknowledged.

\section{REFERENCES}

1. Amemiya, T. (1985). Advanced econometrics: Harvard University Press.

2. Bai, L., Liu, P., Chan, C.-Y., Li, Z. (2017). Estimating level of service of mid-block bicycle lanes considering mixed traffic flow. Transp. Res. Part A Policy Pract., 101, 203-217. https://doi.org/10.1016/j.tra.2017.04.031

3. Bai, L., Liu, P., Liang, Q., Chan, C.-Y., Yu, H. (2017). Estimating the Capacity of Mid-block Bicycle Lanes Considering Mixed Traffic Flow. In Proceedings of the Transportation Research Board 96th Annual Meeting, Washington, DC, USA, 8-12 January

4. Blau, M., Akar, G., Nasar, J. (2018). Driverless vehicles' potential influence on bicyclist facility preferences. Int. J. Sustain. Transp., 12, 665-674. https://doi.org/10.1080/15568318.2018.1425781

5. Carter, D. L., Hunter, W. W., Zegeer, C. V., Stewart, J. R., \& Huang, H. (2007). Bicyclist intersection safety index. Transportation Research Record, 2031, 18. https://doi.org/10.3141/2031-03

6. Chen, X., Yue, L., Han, H. (2018). Overtaking Disturbance on a Moped-Bicycle-Shared Bicycle Path and Corresponding New Bicycle Path Design Principles. J. Transp. Eng. Part A Syst., 144, 04018048. https://doi.or g/10.1061/JTEPBS.0000172

7. De Angelis, M., Stuiver, A., Fraboni, F., Prati, G., Puchades, V.M., Fassina, F., de Waard, D., Pietrantoni, L. (2019). Green wave for cyclists: Users' perception and preferences. Appl. Ergon., 76, 113-121. https://doi.org/10.1016/j.apergo.2018.12.008

8. DelDOT. (2011). Delaware Department of Transportation, Road design Manual. Retrieved at: http://www.deldot.gov/information/pubs_forms/manuals/road_design

9. Dowling, R. (1994). Use of default parameters for estimating signalized intersection level of service. Transportation Research Record (1457).

10. Dozza, M., Piccinini, G.F.B., Werneke, J. (2016). Using naturalistic data to assess e-cyclist behavior. Transp. Res. Part F Traffic Psychol. Behav., 41, 217-226. https://doi.org/10.1016/j.trf.2015.04.003

11. Epperson, B. (1994). Evaluating suitability of roadways for bicycle use: Toward a cycling level-of-service standard. In Transportation Research Record 1438, TRB, National Research Council Board, Washington, DC.

12. FDOT. (2009). Quality/Level of Service Handbook, Florida Department of Transportation (www.dot.state.fl.us); at www.dot.state.fl.us/planning/systems/sm/los/

13. Fernández-Heredia, Á., Jara-Díaz, S., Monzón, A. (2016). Modelling bicycle use intention: The role of perceptions. Transportation, 43, 1-23. https://doi.org/10.1007/s11116-014-9559-9

14. Figueira, J., Ehrgott, M., \& Greco, S. (Eds) (2006). Multiple criteria decision analysis: state of the art surveys. International Series in Operations Research \& Management Science, 78, Springer Verlag. https://doi.org/10.1007/b100605 
15. Fishman, E., Cherry, C. (2016). E-bikes in the Mainstream: Reviewing a Decade of Research. Transp. Rev., 36, 72-91. https://doi.org/10.1080/01441647.2015.1069907

16. Fu, L.; Farber, S. (2017). Bicycling frequency: A study of preferences and travel behavior in Salt Lake City, Utah. Transp. Res. Part A Policy Pract., 101, 30-50. https://doi.org/10.1016/j.tra.2017.05.004

17. Gårder, P., Leden, L., \& Thedéen, T. (1994). Safety implications of bicycle paths at signalized intersections. Accident Analysis \& Prevention, 26(4), 429-439. https://doi.org/10.1016/0001-4575(94)90034-5

18. Ghodrat Abadi, M., Hurwitz, D.S. (2018). Bicyclist's Perceived Level of Comfort in Dense Urban Environments: How do Ambient Traffic, Engineering Treatments, and Bicyclist Characteristics Relate? Sustain. Cities Soc., 40, 101-109. https://doi.org/10.1016/j.scs.2018.04.003

19. Greene, W. H., \& Hensher, D. A. (2010). Modelling ordered choices. A primer. Cambridge University Press. https://doi.org/10.1017/CBO9780511845062

20. Greibe, P., Buch, T.S. (2016). Capacity and Behaviour on One-way Cycle Tracks of Different Widths. Transp. Res. Procedia, 15, 122-136. https://doi.org/10.1016/j.trpro.2016.06.011

21. Hankey, S., Lindsey, G., Wang, X., Borah, J., Hoff, K., Utecht, B., \& Xu, Z. (2012). Estimating use of nonmotorized infrastructure: Models of bicycle and pedestrian traffic in Minneapolis, MN. Landscape and Urban Planning, 107(3), 307-316. https://doi.org/10.1016/j.landurbplan.2012.06.005

22. Harkey, D. L., Reinfurt, D. W., \& Knuiman, M. (1998). Development of the bicycle compatibility index. Transportation Research Record: Journal of the Transportation Research Board, 1636(1), 13-20. https://doi.org/10.3141/1636-03

23. HCM. (2000). Highway Capacity Manual, Transportation Research Board, National Research Council, Washington D.C.

24. Heinen, E.; Buehler, R. (2019). Bicycle parking: A systematic review of scientific literature on parking behaviour, parking preferences, and their influence on cycling and travel behaviour. Transp. Rev., 39, 630-656. https://doi.org/10.1080/01441647.2019.1590477

25. Hoogendoorn, S., Daamen, W. (2016). Bicycle Headway Modeling and Its Applications. Transp. Res. Rec. J. Transp. Res. Board, 2587, 34-40. https://doi.org/10.3141/2587-05

26. Hourdos, J., Lehrke, D., Duhn, M., Ermagun, A., Singer-Berk, L., Lindsey, G. (2017). Traffic Impacts of Bicycle Facilities; Minnesota Department of Transportation: St. Paul, MN, USA.

27. Jensen, S. U. (2007). Pedestrian and Bicyclist Level of Service on Roadway Segments. Transportation Research Record: Journal of the Transportation Research Board, 2031(1), 43-51. https://doi.org/10.3141/2031-06

28. Jiang, R., Hu, M.-B., Wu, Q.-S., Song, W.-G. (2016). Traffic Dynamics of Bicycle Flow: Experiment and Modeling. Transp. Sci., 51, 998-1008. https://doi.org/10.1287/trsc.2016.0690

29. Kazemzadeh, K., Laureshyn, A., Ronchi, E., D’Agostino, C., Hiselius, L.W. (2020). Electric bike navigation behaviour in pedestrian crowds. Travel Behav. Soc., 20, 114-121. https://doi.org/10.1016/j.tbs.2020.03.006

30. Krizek, K. J., \& Roland, R. W. (2005). What is at the end of the road? Understanding discontinuities of onstreet bicycle lanes in urban settings. Transportation Research Part D: Transport and Environment, 10(1), 5568. https://doi.org/10.1016/j.trd.2004.09.005

31. Landis, B. W. (1994). Bicycle interaction hazard score: a theoretical model. Transportation Research Record 1438, TRB, National Research Council, Washington, DC, 3-8.

32. Landis, B. W. (1996). Bicycle System Performance Measures: The Interaction Hazard and Latent Demand Score Models. ITE Journal, 66(2), 18-26.

33. Landis, B. W., Vattikuti, V. R., \& Brannick, M. T. (1997). Real-time human perceptions: toward a bicycle level of service. Transportation Research Record: Journal of the Transportation Research Board, 1578(1), 119-126. https://doi.org/10.3141/1578-15

34. Landis, B. W., Vattikuti, V. R., Ottenberg, R. M., Petritsch, T. A., Guttenplan, M., \& Crider, L. B. (2003). Intersection level of service for the bicycle through movement. Transportation Research Record: Journal of the Transportation Research Board, 1828(1), 101-106. https://doi.org/10.3141/1828-12

35. Liang, X., Xie, M., Jia, X. (2018). New Microscopic Dynamic Model for Bicyclists' Riding Strategies. J. Transp. Eng. Part A Syst., 144, 04018034. https://doi.org/10.1061/JTEPBS.0000148

36. Liang, X., Xie, M.Q., Jia, X.D. (2017). Use of entropy to analyze level of service of dedicated bike lanes in China. Adv. Mech. Eng., 9, 12. https://doi.org/10.1177/1687814017711857

37. Lindsey, G., Hoff, K., Hankey, S., \& Wang, X. (2012). Understanding the Use of Non-Motorized Transportation Facilities. Minnesota: Centre for Transportation Studies

38. Lu, M., Blokpoel, R., Joueiai, M. (2018). Enhancement of safety and comfort of cyclists at intersections. IET Intell. Transp. Syst., 12, 527-532. https://doi.org/10.1049/iet-its.2017.0250

39. Mertens, L., Van Dyck, D., Ghekiere, A., De Bourdeaudhuij, I., Deforche, B., Van de Weghe, N., Van Cauwenberg, J. (2016). Which Environmental Factors Most Strongly Influence a Street's Appeal for Bicycle Transport Among Adults? A Conjoint Study Using Manipulated Photographs. Int. J. Health Geogr, $15,31$. https://doi.org/10.1186/s12942-016-0058-4

40. Mohammed, H., Bigazzi, A.Y., Sayed, T. (2019). Characterization of bicycle following and overtaking manoeuvres on cycling paths. Transp. Res. Part C Emerg. Technol., 98, 139-151. https://doi.org/10.1016/j trc.2018.11.012 
41. Muñoz, B., Monzon, A., López, E.(2016). Transition to a cyclable city: Latent variables affecting bicycle commuting. Transp. Res. Part A Policy Pract., 84, 4-17. https://doi.org/10.1016/j.tra.2015.10.006

42. Nelder, J. A., \& Wedderburn, R. W. M. (1972). Generalized Linear Models. Journal of the Royal Statistical Society. Series A (General), 135(3), 370-384. https://doi.org/10.2307/2344614

43. Okon, I., \& Moreno, C. (2019). Bicycle level of service model for the cycloruta, Bogota, Colombia. Romania Journal of Transportation, 8(1) 1-33. https://doi.org/10.2478/rjti-2019-0001

44. Okon, I., Brussel, M. J., van den Bosch, F. H., Moreno, C. A., \& van Maarseveen, M. (2017). A Statistical approach to the estimation of bicycle level of service models for the Cicloruta in Bogota, Colombia. In Urban Transport XXIII: 176, 265-282, WIT Press Publishing. https://doi.org/10.2495/UT170231

45. Plaut, P. O. (2005). Non-motorized commuting in the US. Transportation Research Part D: Transport and Environment, 10(5), 347-356. https://doi.org/10.1016/j.trd.2005.04.002

46. Pokorny, P., Pitera, K. (2019). Observations of truck-bicycle encounters: A case study of conflicts and behaviour in Trondheim, Norway. Transp. Res. Part F Traffic Psychol. Behav., 60, 700-711. https://doi.org/10 .1016/j.trf.2018.11.018

47. Providelo, J. K., \& da Penha Sanches, S. (2011). Roadway and traffic characteristics for bicycling. Transportation, 38(5), 765-777. https://doi.org/10.1007/s11116-011-9353-X

48. Pu, Z., Li, Z., Wang, Y., Ye, M., \& Fan, W. D. (2017). Evaluating the interference of bicycle traffic on vehicle operation on urban streets with bike lanes. Journal of advanced transportation, 2017. https://doi.org/10.1155/2017/6973089

49. Sanders, R.L. (2016). We can all get along: The alignment of driver and bicyclist roadway design preferences in the San Francisco Bay Area. Transp. Res. Part A Policy Pract., 91, 120-133. https://doi.org/10.1016 j.tra.2016.06.002

50. Schleinitz, K., Petzoldt, T., Franke-Bartholdt, L., Krems, J., Gehlert, T. (2017). The German Naturalistic Cycling Study-Comparing Cycling Speed of Riders of Different E-Bikes and Conventional Bicycles. Saf. Sci., 92, 290-297. https://doi.org/10.1016/j.ssci.2015.07.027

51. Sorton, A., \& Walsh, T. (1994). Bicycle stress level as a tool to evaluate urban and suburban bicycle compatibility. Transportation Research Record, TRB, National Research Council, Washington, D. C., 17-24.

52. Summala, H., Pasanen, E., Räsänen, M., \& Sievänen, J. (1996). Bicycle accidents and drivers' visual search at left and right turns. Accident Analysis \& Prevention, 28(2), 147-153. https://doi.org/10.1016/00014575(95)00041-0

53. Tan, D., Wang, W., Lu, J., \& Bian, Y. (2007). Research on Methods of Assessing Pedestrian Level of Service for Sidewalk. Journal of Transportation Systems Engineering and Information Technology, 7(5), 74-79. https://doi.org/10.1016/S1570-6672(07)60041-5

54. TRANSMILENIO. (2013). TRANSMILENIO S.A. - Estadísticas Generales. http://www.transmilenio.gov.c o/WebSite/Contenido.aspx?ID_REDIRECT=TransmilenioSA_TransmilenioEnCifras_EstadisticasGenerales

55. Vasudevan, V., Patel, T. (2017). Comparison of Discomfort Caused by Speed Humps on Bicyclists and Riders of Motorized Two-Wheelers. Sustain. Cities Soc., 35, 669-676. https://doi.org/10.1016/j.scs.2017.08.032

56. Wang, Y., \& Nihan, N. L. (2004). Estimating the risk of collisions between bicycles and motor vehicles at signalized intersections. Accident Analysis \& Prevention, 36(3), 313-321. https://doi.org/10.1016/S0001$\underline{4575(03) 00009-5}$

57. Washington, S. P., Karlaftis, M. G., \& Mannering, F. L. (2011). Statistical and econometric methods for transportation data analysis. CRC press.

58. Xu, L., Liu, M., Song, X., Jin, S. (2018). Analytical Model of Passing Events for One-Way Heterogeneous Bicycle Traffic Flows. Transp. Res. Rec. J. Transp. Res. Board, 2672, 125-135. https://doi.org/10.11 77/0361198118788425

59. Ye, X., Yan, X., Chen, J., Wang, T., Yang, Z. (2018). Impact of Curbside Parking on Bicycle Lane Capacity in Nanjing, China. Transp. Res. Rec. J. Transp. Res. Board, 2672, 120-129. https://doi.org/10.11 77/0361198118758334

60. Zhang, L., \& Prevedouros, P. D. (2003). Signalized intersection level of service incorporating safety risk. Transportation Research Record: Journal of the Transportation Research Board, 1852(1), 77-86. https://doi.org/10.3141/1852-11 